\author{
The journal editor: friend or foe? \\ Jenny Hall \\ Vanora Hundley \\ Edwin van Teijlingen \\ CMMPH, Bournemouth University
}

\begin{abstract}
:
The role of the journal editor is often unknown by many authors. The purpose of this article is to explain the role with the aim of educating authors and to encourage future participation in reviewing and publication. Illustration is provided of the publishing process.
\end{abstract}

Keywords: Editor role; writing; publication, reviewing

\title{
Introduction
}

There are numerous books and articles on how to get academic work into print, however within these the role of the journal editor is rarely visible. The editor it is suggested conducts his or her work quietly in the background, and most authors take little notice other than to address their cover letter to the editor (Anderson, 2014). Yet understanding the role of the editor is key for authors aiming to get their work into print. Over the past decade the authors of this paper have been involved in a series of talks and training sessions to help early career researchers and clinicians to get published in academic journals. It is clear from the kinds of questions raised in sessions on academic writing, that many budding authors do not know or understand the role of a journal editor.

This paper outlines key aspects of the editor's role, offers insights into the process of submitting a journal article and highlights the need for journal instructions and for authors to follow them. The intention is to make potential authors think actively about the process of submitting an article and the reasons why it is important to follow authors' instructions. The paper provides an insight into the role of the editors, who may be busy professionals, who doing the editorial work in their own time over and above the day job of academic lecturer, researcher and/or practitioner. It is often the case that the work of an editor gets done over the weekend or in the evenings after the 'day job' has been attended to.

\section{The role of the Editor}

The first step in demystifying the role of the academic journal editor is to note that an editor does a lot of things, but rarely 'edits' in the sense of substantive editing, line editing, or 'copy editing', although there are exceptions with regard to editing language and terminology to make it appropriate and acceptable. The editor's role includes:

- maintaining the standards of the journal. In that sense the editor is the gate keeper who keeps papers out that are just not good enough. This includes filtering out manuscripts that do not fit the aims and objectives of the journal. 
- $\quad$ setting the journal's strategic direction. In order to do this the editor needs to be aware of what will 'sell' the journal: what the readership will be interested in reading and what is topical. This means knowing the readership and perhaps changing content to encourage readers from other professional groups. It also means being aware of important professional issues or political drivers affecting the readers;

- guiding ethical standards of the journal. This may be ethical standards related to research and writing, especially plagiarism, but it may also relate to understanding marketing ploys by companies that may want access to the journal's audience/subscribers;

- encouraging the submission of high quality papers. This may include selecting 'themes' for the journal and commissioning some papers around a particular subject;

- preventing academic fraud and avoiding plagiarism;

- ensuring appropriate content, including making decisions about the right pictures to support a manuscript and accepting / rejecting advertising; promoting the journal at academic conferences;

- $\quad$ selecting reviewers for submitted manuscripts;

- corresponding with authors;

- and, corresponding with readers.

It may not be surprising to find that editors and authors often have different perspectives. For example, the authors may think their title is clever, fashionable, funny or catchy, but the editor is probably asking herself: "Does this title explain what the paper is about?" and "Will this title still make sense to the readership in a decade?" Does the paper link to a hot topic in the media? Does the paper have a decent lifespan? Has there already been an article on this topic recently?

The editor also has a role in ensuring the paper addresses a wide ranging audience. For example, the author's perspective can be very 'local' rather than 'global'. The role of the editor (and reviewers) is to ensure that general aspects of local issues are picked out to make such article relevant when writing for an international journal. The author may need to be encouraged to widen their view to ensure relevance.

Editors may also consider the balance of papers in a particular issue. For example, ensuring a balance between different types of papers, some empirical, data-based articles, reflections, reviews, theoretical and clinical papers. Or a mix of papers from different parts of the world or submitted by authors based in different disciplines. Sometimes an editor may hold back a paper for the next issue because the current issue has already two or three papers from Nepal, or on barriers to antenatal care or student reflections on midwifery education. Sometimes an editor may hasten the publication of a paper which based on a major political reports or important new research evidence. If the editor needs to bring a publication out quickly, this may result in moving already accepted papers to a later issue.

The Editor also has an important role in linking with publishers and editorial teams who provide the sub-editing and production of proofs. Professional editors sometime have to educate publishers who are not aware of midwifery or to advise sub-editors who may not recognise the midwifery terms used. Occasionally this can be challenging as many publishing houses are big businesses and often are more concerned about financial and legal issues than ethics and academic debate. 


\section{The journey of a paper through the review process}

Figure 1 gives a simplistic outline of the editorial process that starts with a review by the editor. . Often editors do not have enough time to read a whole paper and for the initial submission will rely on the title and abstract as windows to the study. They may only read the abstract, and perhaps skim the paper, in order to make a decision about whether to send out the paper for review or to reject it. In the health field editors normally also check whether or not a primary study has been granted ethical approval.

Each journal has clear instructions to authors and it is important that authors follow them. An abstract should be written according to the protocol of the journal. If the guidance has not been adhered to then many editors will reject the paper without getting into the main text. Failure to follow instructions may mean that you do not even pass the first hurdle.

Papers may also be rejected at this stage because they do not cover an appropriate topic or are not of sufficient quality to be sent to the reviewers. The editor may offer advice to submit to a different journal or direct the author on how to gain support with academic writing or the standard of the written language is not good enough.

\section{Figure 1 The 'career' of your manuscript under review}

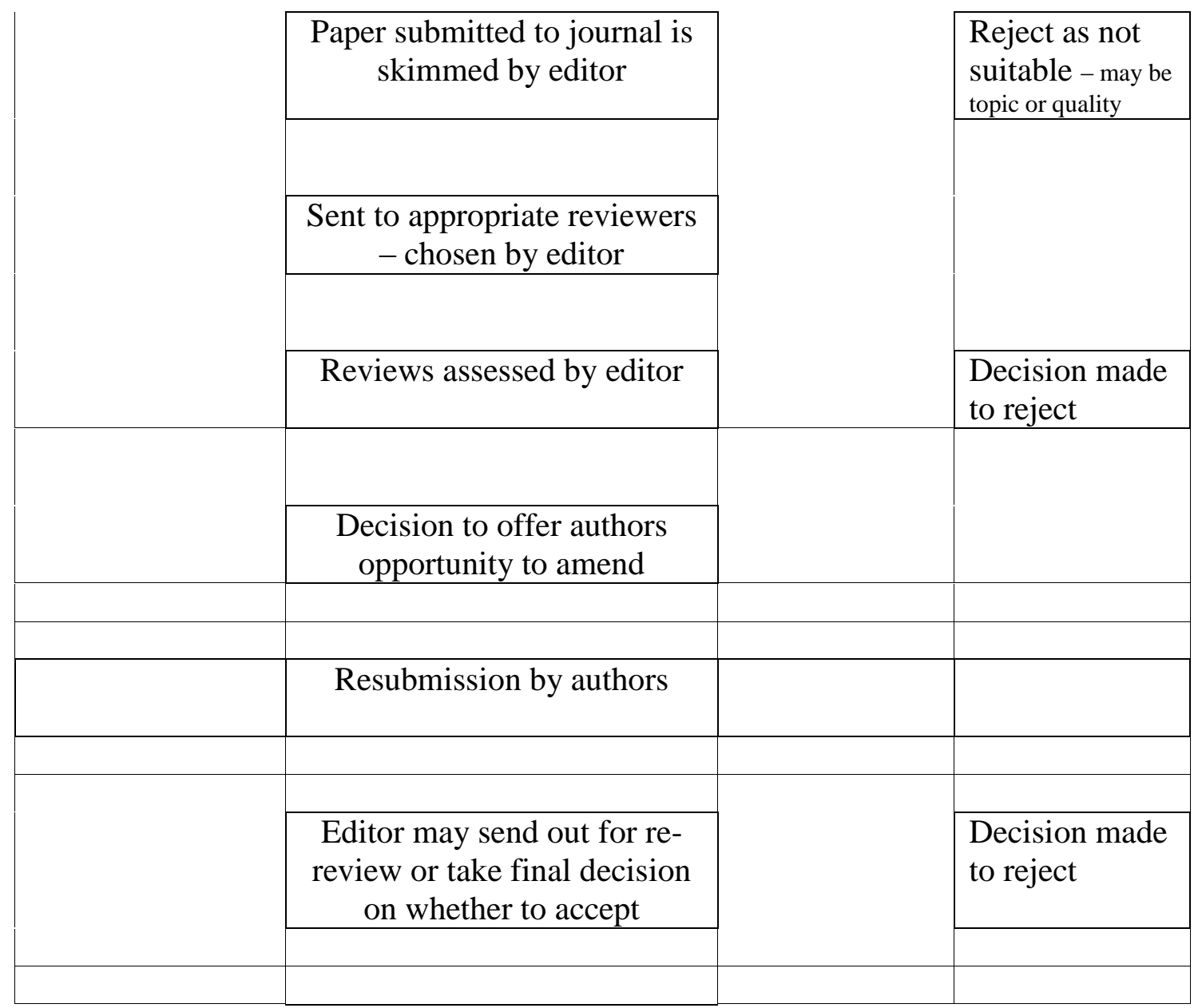


Paper appears in print, often online first

If the editor decides that the paper is of interest and relevant to the journal then it will be sent to reviewers who usually have expertise in the subject or methods. Obtaining the correct reviewer can be a minefield, especially for a truly specialist subject. Good reviewers are difficult to find, as many are themselves overburdened by requests to review for several different papers.

Reviewers are given a deadline by which to review and return their comments. However, they are also busy clinicians, academics or researchers who do the reviewing as volunteers, so this process may take a significant time. Reviewers who accept may not deliver their review on time, even with the best intentions. The editor has very little leverage over a peer reviewer who has promised to review but does not deliver. However, increasingly journal editors are imposing response times after which they will 'terminate that reviewer' in order to keep the review process moving (Fahy, 2014). Thus the processes outlined above may take a number of weeks if not months. A journal should highlight in the instructions the time it takes for a review process to be completed. The author should wait until this time has passed before contacting an editor to establish the decision on a paper.

The editor may have to do further reading of the paper in more detail when the reviewers' reports come back, especially if the reviewers contradict each other. The editor as a 'judge' ends up acting as an additional reviewer to establish whose view is more appropriate. Occasionally when there is a lack of agreement by two reviewers the editor may send out the paper to a third or fourth reviewer (particularly if additional methodological or statistical advice is needed). Sometimes the editor may act as the third reviewer depending on the subject. The editor then needs to recommend the changes that the authors are required to make, and whether additional analysis or information is necessary. This demonstrates that an editor's role is time consuming.

When an author gets her paper back with the message that minor or major changes are required, she needs to address these in order. In responding the author should include a cover letter to the editor outlining point by point what and where in the resubmission she has improved the manuscript. With minor revisions the editor may make the decision to accept on the basis of this cover letter, if the revised paper is sent back to the original reviewers then the letter is likely to speed up the review process.

It is worth noting here that both authors and reviewers should use respectful and civil language (Sternberg, 2002). All journals subscribe to the idea of balanced reviews, and thus harmful 'savage' reviews should be a thing of the past. It is proposed that balanced reviews are more likely where open peer review is used. The BMC series utilises open peer review for medical journals. They describe the process as:

"the reviewers' names are included on the peer review reports, and if the manuscript is published, the reports are made available online along with the final version of the manuscript." (BMC, nd)

Others have suggested that open peer review simply leads to an "accumulation of 'enemies' who may later try to torpedo one's own manuscripts or grant applications" (Decoursey, 2006). Concern about the peer review process has led the Committee on Publication Ethics (COPE) to draw up Ethical Guidelines for Peer Reviewers that sets out the basic principles and standards to which all peer reviewers should adhere (2013). 
The editor of Women and Birth recently decided to highlight select papers in each issue, publishing the reviewers' comments, with the intention of stimulating interest in the review process (Fahy, 2014).

\section{Why do people take on the role of being an editor?}

There are a number of advantages of being an editor. These include:

- getting to read new research or new theoretical perspectives 'hot-off-the press' before most other people see it. This is a perk for reviewers too, of course.

- helping others to develop. It is very satisfying to encourage new authors to submit papers and to support students, particularly those without English as their first language.

- continuing to develop your expertise. Being an editor allows you to develop a better understanding of research methods that might be outside of your area of expertise, and to continue to develop your writing skills.

- being an editor is part of wider scholarship and for some a stepping stone in their career or and aid to get the desired chair at a well-known institution.

Another advantage of being an editor, is getting known in the field. However with the role comes responsibility. Editors need to be aware of their powers and the associated responsibilities.

Editors are gate keepers in the world of academia, they control and potentially limit the dissemination of new ideas/approaches. They act as gatekeepers, both in terms of the papers they accept or reject and in the way academic ideas progress. Editors should be up-to-date and aware of the policies and current affairs underpinning their discipline and/or field. They should connect in with influential people and stakeholders of the profession, for example, through choosing a broad spectrum editorial board that can provide support and influence. Editors need to be open to a range of approaches and methodologies in their field and discipline. Editors need to help set and address the agenda and help develop scholarship in their academic discipline and/or profession through advice and education. A good editor, in our view, should be able to say: "that is not the way that I would have done it, but there is some merit in it, let's put it out for academic debate in our journal." We can also promote under-researched areas, put out calls for special issues on selected topics, geographical areas or methodologies.

Editors need to have a thick skin as authors, would-be authors and failed authors can and will complain. Complaints may be about word limits, deadlines, reviewers' misunderstanding the authors' paper or spent time waiting for your decision. Reviewers have been known to complain too, for example about being ignored. Contradicting points of view on a paper from two eminent reviewers can raise challenges for an editor; does she ignore one, , and run the risk of upsetting that person. 
Sometimes editors make genuine mistakes such as misunderstanding a reviewer's report, or trusting one particular (normally reliable reviewer too much who had an off-day), or sending the wrong email to an author or reviewer. The editor may select or accept to picture to illustrate an article that offends certain reader. Such mistakes often arise because the editor is slightly too tired at eleven o'clock at night. Time management is a key challenge for an editor because the arrival,of manuscripts is unpredictable. The editor may plan to spend time handing one particular manuscript and then get two new submissions and three papers returned that have been under review. Both reviewers and authors' timing of their 'delivery' is as unpredictable as a baby's arrival!

KEY Messages for potential authors Understanding what an editor does can make the process easier. It is important to have patience because the submission process may take a long time.

- Editors have little time. They are generally busy professionals, who are not being paid for being an editor.

- Become a reviewer: get to know the standard and way of presenting papers.

- Offer to join an Editorial board and help steer direction of publications

- Guest editors -be prepared to contact an editor to discuss whether a particular 'hot topic' or theme could be included in the journal. There are often opportunities to write for special issues or even become a Guest editor!

\section{Conclusion}

Journal editing is not a role to be taken lightly. There is responsibility in ensuring that quality research, review and educational papers are published for the development of the profession. It is also often an 'add-on' to the usual working day and the editor will have to be prepared to work long hours on occasions in order to meet deadlines. On the other hand it provides an opportunity to link in with the wider profession and other groups and to keep up-to-date with current trends as well as influence what is being published. This paper has i discussed the role of the editor with the aim of providing an insight into what happens when an author sends an article for publication and to encourage you in the future to participate in the publishing process.

\section{References}

Anderson K (2014) The Editor - A Vital Role We Barely Talk About Anymore. The Scholarly Kitchen http://scholarlykitchen.sspnet.org/2014/09/23/the-editor-a-vital-role-webarely-talk-about-anymore/

BMC (nd) What is 'open peer review', as operated by the medical journals in the BMC series? http://www.biomedcentral.com/authors/authorfaq/medical

COPE (2013) Ethical Guidelines for Peer Reviewers http://publicationethics.org/files/Ethical_guidelines_for_peer_reviewers_0.pdf 
Decoursey T (2006) Perspective: The pros and cons of open peer review: Should authors be told who their reviewers are? Nature doi:10.1038/nature04991

http://www.nature.com/nature/peerreview/debate/nature04991.html

Fahy K (2014) Keeping Women and Birth at the cutting edge of quality journal publishing. Women and Birth 27 (1): 1.

Sternberg RJ (2002) On Civility in Reviewing. Association of Psychological Science Observer Archive 15 (1): http://www.psychologicalscience.org/observer/0102/prescol.html

Background

Dr. Jenny Hall is a Sub-Editor for Women and Birth and was the editor of The Practising Midwife for 10 years, as well as commissioner and reviewer for midwifery text books. Both Prof. Vanora Hundley and Prof. Edwin van Teijlingen are Associate Editors for BMC Pregnancy \& Childbirth. Between them the authors are (or have been) members of more than ten editorial boards for other journals. 